\title{
Gamma Knife radiosurgery for brain metastasis: review of 103 patients
}

Marcos Antônio Dellaretti Filho',2, George de Albuquerque Cavalcanti Mendes ${ }^{3}$, Nicolas Reyns², Gustavo Touzet², François Dubois², Eric Lartigau², Serge Blond²

\section{ABSTRACT}

Objective: To assess clinical and imaging outcomes in patients treated with Gamma Knife stereotactic radiosurgery (SRS) for brain metastasis. Methods: One hundred and three patients with 158 intracranial metastasis consecutively underwent Gamma Knife SRS between January, 2004 and December, 2006. The results were based on last imaging and the date of the last visit. Average age of the patients was 56 years (range 32-84 years). Karnofsky performance status average was 87.6. Fifty-eight (56.3\%) patients had single brain metastasis. The average tumor volume was 2.5cc (range 0.02-16.6 cc). The SRS marginal dose average was 23.4 Gy (range 15-25 Gy). Results: Treatment sequence was SRS alone (89 patients) or SRS plus whole-brain radiotherapy (WBRT) (14 patients). The 1-year local control was $80 \%$, being better for tumors with volume $<5 c c$ than for $\geq 5$ cc: $86 \%$ vs $53 \%(p<0.05)$. The 1 -year distant brain metastasis-free survival incidence was $73 \%$. The initial number of brain lesions (single vs multiple) was not a significant factor on distant brain metastasis: free survival at 1 year was $75 \%$ for single metastases and $70 \%$ for multiple lesions. Renal cancer was the only factor with a significant effect on distant brain metastasis. The median overall survival was 15 months. According to unifactorial and multifactorial analysis, three prognostic factors for overall survival were retrieved recursive partitioning analysis (RPA) class, Karnofsky index performance and tumor volume. Conclusion: In this series, SRS provided excellent local control with relatively low morbidity in patients with brain metastases.

\section{KEY WORDS}

Brain metastasis. Radiosurgery. Gamma Knife.

\section{RESUMO}

Radiocirurgia com Gamma Knife para metástases cerebrais. Análise de 103 casos

Objetivo: Avaliar o seguimento clínico e imaginológico de pacientes tratados com radiocirurgia estereotáxica $(R C)$ utilizando Gamma Knife para metástases cerebrais. Casuística e método: Cento e três pacientes com 158 metástases intracranianas tratados com Gamma Knife entre janeiro de 2004 e dezembro de 2006. Os resultados foram baseados no último exame de imagem e na visita mais recente. A média de idade foi 56 anos (32 a 84 anos). O índice de Karnofsky médio foi 87,6. Cinquenta e oito $(56,3 \%)$ pacientes tiveram metástases cerebrais únicas. A média de volume do tumor foi $2,5 c c$ (0,02-16,6cc). A dose marginal média foi 23.4Gy (15-25Gy). Resultados: Em 89 pacientes foi realizado apenas $R C$ isolada e em 14 pacientes, $R C$ e radioterapia craniana total (RCT). A taxa de controle local em um ano foi $80 \%$, sendo melhor para tumores de volume < 5 cc do que quando $\geq 5 \mathrm{cc:} 86 \%$ versus $53 \%$ $(p<0,05)$. A sobrevida de um ano livre de metástase cerebral distante foi observada em $73 \%$. O número inicial de lesões cerebrais (única versus múltipla) não foi fator significativo para o desenvolvimento de metástases a distância: a sobrevida livre em um ano foi $75 \%$ para metástases únicas e $70 \%$ para lesões múltiplas. O câncer renal foi o único fator de efeito significativo para o desenvolvimento de metástases cerebrais a distância. A sobrevida global em um ano foi 70\%. De acordo com a análise unifatorial e multifatorial, três fatores prognósticos foram encontrados: classe RPA (recursive partitioning analysis), indice de Karnofsky e volume tumoral. Conclusão: Nesta série, a RC proporcionou um excelente controle local com baixa morbidade relativa em pacientes com metástases cerebrais.

\section{PALAVRAS-CHAVE}

Metástase cerebral. Rradiocirurgia. Gamma Knife.

1 Medical Assistant, Department of Neurosurgery, Santa Casa Hospital, Belo Horizonte, Brazil. 


\section{Introduction}

Brain metastasis represent an increasingly common complication of systemic cancer. It is estimated that approximately $20 \%$ to $40 \%$ of patients with systemic cancer develop brain metastasis, the majority of which are associated with significant morbidity and mortality. ${ }^{4,13}$ Stereotactic radiosurgery (SRS) is emerging as an excellent therapy to achieve local control of brain metastasis of $\leq 3 \mathrm{~cm}$ in diameter and as a noninvasive alternative to surgical resection for selected lesions. ${ }^{1}$ Once a brain metastasis has been diagnosed, the mean life expectancy is less than one year. However, in many patients, aggressive treatment of metastatic disease has been shown to restore neurological function and prevent further neurological manifestations. The optimum treatment for metastatic brain disease is often discussed in the literature. ${ }^{17,19}$

The purpose of this study is to assess clinical and imaging outcomes in patients treated with Gamma Knife stereotactic radiosurgery (GK) for brain metastasis so as to evaluate prognostic factors for local control, survival and incidence of distant brain metastasis.

\section{Patients and methods}

The medical records of 103 patients with 158 brain metastasis (range 1 to 10 metastasis, mean 1.5/patient) treated between January, 2004 and December, 2006 at Hospital Roger Salengro (Lille, France) were retrospectively reviewed. Age average was 56 years (range 32-84 years). Karnofsky performance status (KPS) average was 87.6. The average tumor volume was $2.5 \mathrm{cc}$ (range $0.02-16.6 \mathrm{cc}$ ). The mean SRS marginal dose was 23.4 Gy (range 15-25 Gy). The other characteristics of the patients are outlined in Table 1. Follow-up information was available for all patients.

The brain metastasis diagnosis was based on neuroimaging findings and on the diagnosis of the primary tumor.

\section{Radiosurgical procedures}

All patients were treated with Leksell Gamma Knife, model B (Elekta AB, Stockholm, Sweden). The procedure on the day of SRS treatment started with application of the Leksell stereotactic frame (Elekta Instrument AB, Stockholm, Sweden) to the patient's head after local anesthesia. After the frame fixation, magnetic resonance (MR) and computed tomography (CT) imaging were used for dose planning with Leksell Gamma Plan (Elekta Instrument AB). The MR images

\begin{tabular}{|c|c|}
\hline \multicolumn{2}{|c|}{$\begin{array}{c}\text { Table } 1 \\
\text { Overall characteristics }\end{array}$} \\
\hline Characteristics & Value \\
\hline Male/Female & $61 / 42$ \\
\hline \multicolumn{2}{|c|}{ Primary tumor site } \\
\hline Lung & 46 \\
\hline Breast & 18 \\
\hline Renal & 15 \\
\hline Melanoma & 12 \\
\hline Gastrointestinal & 6 \\
\hline Other & 6 \\
\hline \multicolumn{2}{|l|}{ RPA Class } \\
\hline Class I & 28 \\
\hline Class II & 65 \\
\hline Class III & 10 \\
\hline \multicolumn{2}{|l|}{ KPS Score } \\
\hline $\mathrm{KPS} \geq 70$ & 81 \\
\hline KPS $<70$ & 22 \\
\hline \multicolumn{2}{|c|}{ Volume of brain metastasis } \\
\hline $\mathrm{Vol} \geq 5 \mathrm{cc}$ & 27 \\
\hline $\mathrm{Vol}<5 \mathrm{cc}$ & 127 \\
\hline \multicolumn{2}{|c|}{ SRS dose at the tumor margin } \\
\hline Dose $\geq 24$ Gy & 113 \\
\hline Dose 21- 24 Gy & 10 \\
\hline Dose $<21 \mathrm{~Gy}$ & 31 \\
\hline
\end{tabular}

were calibrated before examination and verified by comparison with the $\mathrm{CT}$ images for each patient in order to minimize magnetic distortion errors. Treatment planning was performed by a neurosurgeon, who used MR imaging volumetric acquisition or T1-weighted images with Gd contrast to define the volume of the lesion. All plans were reviewed by the medical physicist. Treatment doses for each lesion were based on the dose criteria established in RTOG 95-08. ${ }^{2}$

\section{Follow-up evaluation}

Neurological examination and tumor response as verified by MR scans were used to evaluate patients during follow-up. Follow-up examinations were performed at 3 and 6 months after radiosurgery. Local disease recurrence was defined as the reappearance of a metastasis at exactly the same site as the first metastasis, and distant disease recurrence was defined as the appearance of a new brain metastasis at a site different from that of the original metastasis detected by the MR scan.

The cause of death was determined from medical records and from referring physician's correspondence or supplementary phone calls. Patients with stable extra-cerebral disease and progressive neurological dysfunction, patients with severe neurological disability dying from intercurrent illness, and patients with progressive systemic and neurological disease were considered to have experienced neurological death. Otherwise, systemic death was assumed. 


\section{Statistical methods}

Data analysis was performed using Epi info 6.02 and Medcalc 9.3.0.9. The reference point of the study was the date of the radiosurgical procedure. The endpoints were death, date of local disease recurrence and distant disease recurrence. The length of survival was estimated using the Kaplan-Meier curves method. ${ }^{10}$ Comparison of Kaplan-Meier curves was performed with the log-rank statistic. The prognostic value of the individual covariates was obtained from the Cox proportional hazards model. Variables used for univariate and multivariate analyses were dichotomized. The correlation between prognostic factors was analyzed using chi-square statistic. The following variables were tested: age at radiosurgery ( $>65$ years vs $\leq 65$ years); KPS pre-treatment ( $<70$ vs $\geq 70)$; metastasis volume ( $<5 \mathrm{cc}$ vs $\geq 5 \mathrm{cc}$ ); number of brain metastases (single vs multiple); whole brain radiotherapy (WBRT plus SRS vs. SRS alone); recursive partitioning analysis (RPA) class (I vs II vs III); primitive tumor and dose administrated ( $<21$ Gy vs $\geq 21 \mathrm{~Gy}$ and $<24$ Gy vs $\geq 24$ Gy). Parameters were deemed to be statistically significant at a value of $\mathrm{p}<0.05$.

\section{Results}

\section{Patients and tumor characteristics}

The majority of patients was younger than 65 years (83 patients) and had a KPS score greater than 70 (Table 1). In more than half of them, the recursive partitioning analysis (RPA) class was I or II, and only ten patients had RPA class III. Most had a single brain metastasis (58 patients) and 3.9\% had more than three. The majority of metastasis was from lung cancer.

Fourteen patients $(13.6 \%)$ were treated with SRS plus WBRT (30-40 Gy). Twenty-seven patients underwent surgical resection for tumors $>3 \mathrm{~cm}$ in diameter. All brain tumors were treated.

\section{Brain tumor recurrence}

Brain tumor recurrence at either distant or local sites in the brain was observed in 41 patients. The 1-year actuarial rate of brain tumor recurrence-free survival was $64 \%$. The univariate and multivariate analyses revealed that 1-year actuarial rate of brain tumor recurrence-free survival was better in: patients with non-renal cancer than with renal cancer $-68.3 \%$ vs $41.7 \%(\mathrm{p}=0.03)$; and patients with tumor volume $<5 \mathrm{cc}$ than $\geq 5 \mathrm{cc}-73.7 \%$ vs $30.8 \%(p=0.01)$. Comparisons among dose marginal administrated showed that a dose $\geq 24$ Gy resulted in significantly less recurrence than the 21-24Gy and <21Gy: the 1-year actuarial rate of brain tumor recurrence-free survival was $71.8 \%$ vs $56 \%(\mathrm{p}=0.04)$.

Twenty-five patients had new brain metastases at distant sites. The 1-year actuarial rate of distant brain metastasis-free survival was $73 \%$. The analysis revealed that renal cancer (Figure 1) was a significant variable associated with 1-year actuarial rate of distant brain metastasis-free survival: $79.6 \%$ for non-renal cancer and $41.7 \%$ for renal cancer $(\mathrm{p}=0.0009)$.

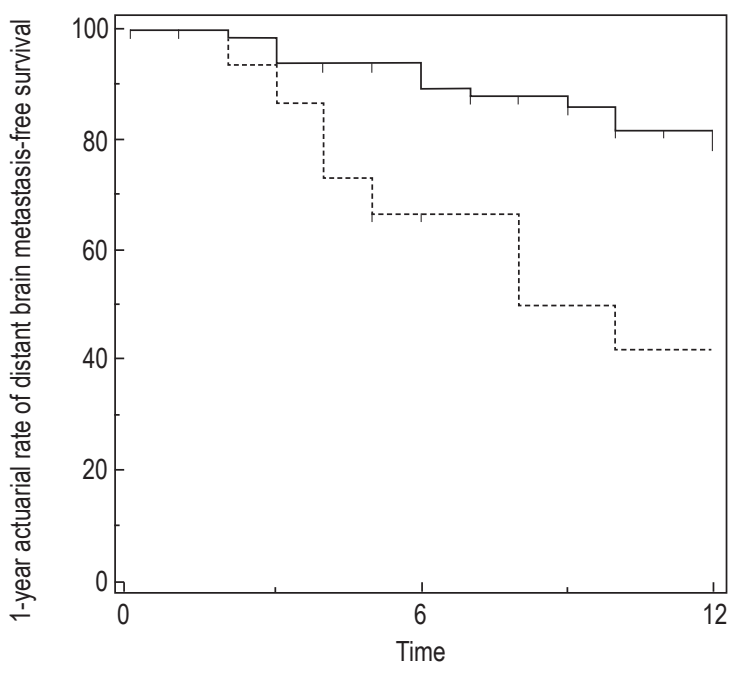

Figure 1-Kaplan-Meier curves for 1-year actuarial rate of distant brain metastasis-free survival. The solid line represents patients who did not have renal cancer; dotted line represents patients with renal cancer.

The 1-year actuarial rate of local tumor control was $81 \%$. Local tumor control was better in patients with tumor volume $<5 \mathrm{cc}$ than $\geq 5 \mathrm{cc}: 83.8 \%$ vs $53.4 \%$ $(p=0.005)$ (Figure 2). Dose administrated (Figure 3 ) was also a significant factor related to 1-year local tumor control: $90.2 \%$ for the dose $\geq 24 \mathrm{~Gy}$ group, $66.7 \%$ for the dose $21-24 \mathrm{~Gy}$ group, and $52.1 \%$ for the dose $<21 \mathrm{~Gy}$ group $(\mathrm{p}=0.0019)$.

Other covariates, such as age at radiosurgery, pretreatment KPS, number of brain metastases, WBRT, RPA class were entered into a Cox model, but none of them were significantly associated with tumor recurrence.

\section{Survival and cause of death}

By the time of the last follow-up visit in December 2007, 72 patients $(69.9 \%)$ had died. Death was attributed to neurological causes in 29 patients $(40.2 \%$ of the deaths).

The median overall survival of the entire study population, measured from the date of SRS, was 15 months. 


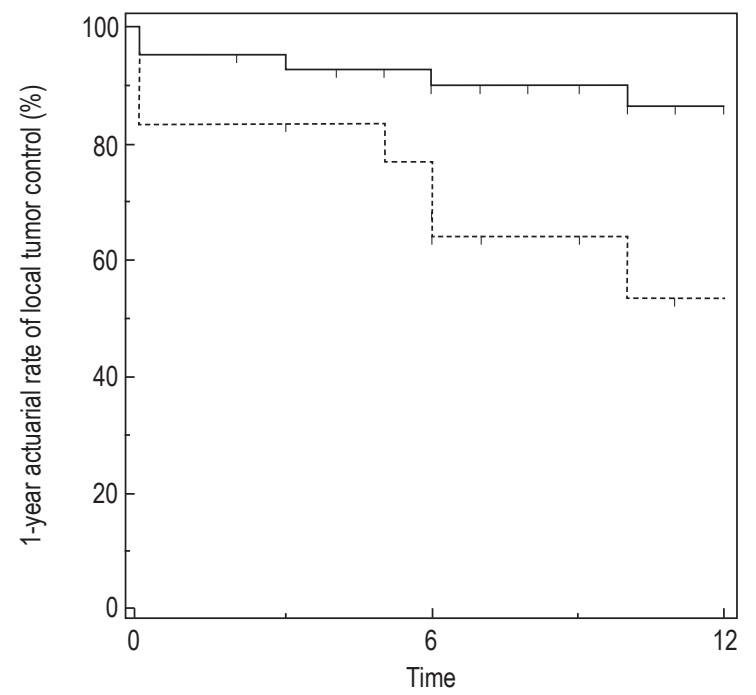

Figure 2-Kaplan-Meier curves for 1-year actuarial rate of local tumor control. The solid line represents tumor volume $<5 \mathrm{cc}$; the dotted line represents tumor volume $>5 \mathrm{cc}$. (Logrank test $p=0.0054)$.

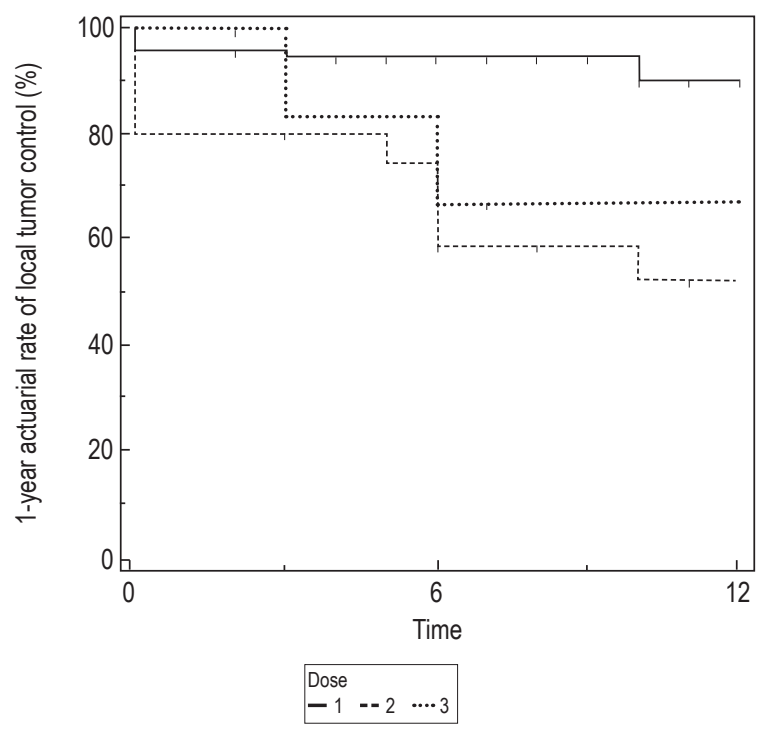

Figure 3 - Kaplan-Meier curves for 1-year actuarial rate of local tumor control. Line 1 represents administrated dose $\geq 24 G y$, line 2 dose $\geq 21 G y$ and $<24$ Gy and line 3 administrated dose $<21 G y$. (Logrank ranktest $=0.0019)$.

The univariate analysis of the patients' characteristics and treatment parameters found three statistical significance factor related to survival: RPA class $(p=0.0001)$, pre-treatment KPS $(p=0.001)$, and metastasis volume $(\mathrm{p}=0.01)$. Note that primary tumor $(\mathrm{p}=0.47)$, age $(\mathrm{p}=0.94)$, WBRT $(\mathrm{p}=0.31)$, number of brain metastasis $(\mathrm{p}=0.12)$ and dose administrated $(\mathrm{p}=0.76)$ did not correlate with outcomes.

The multivariate analysis also demonstrated that RPA class, pre-treatment KPS and metastasis' volume were associated with prognosis of the patients.
The median survival time for patients classified as RPA I, II and III were 20 months, 15 months and 4 months, respectively ( $\mathrm{p}=0.0001, \log$ rank). The 1 -year actuarial survival rates for patients classified as RPA I, II and III were 80.8, 54.1 and 24\% (Figure 4). Patients with KPS $\geq 70$ had 17 months of median survival time while patients with KPS $<70$ had 6 months. The 1-year survival rates for patients with KPS $\geq 70$ and KPS $<70$ were $63.5 \%$ and $40 \%$ respectively ( $\mathrm{p}=0.001$, log rank) (Figure 5). Finally, patients with volume of metastasis $<5 \mathrm{cc}$ had better outcome that patients with metastasis $\geq 5 \mathrm{cc}$ : the median survival time was 17 months vs 9 months, and 1-year actuarial survival rates were $63.6 \%$ vs $28.8 \%$ (Figure 6$)$ ( $\mathrm{p}=0.01, \log$ rank).

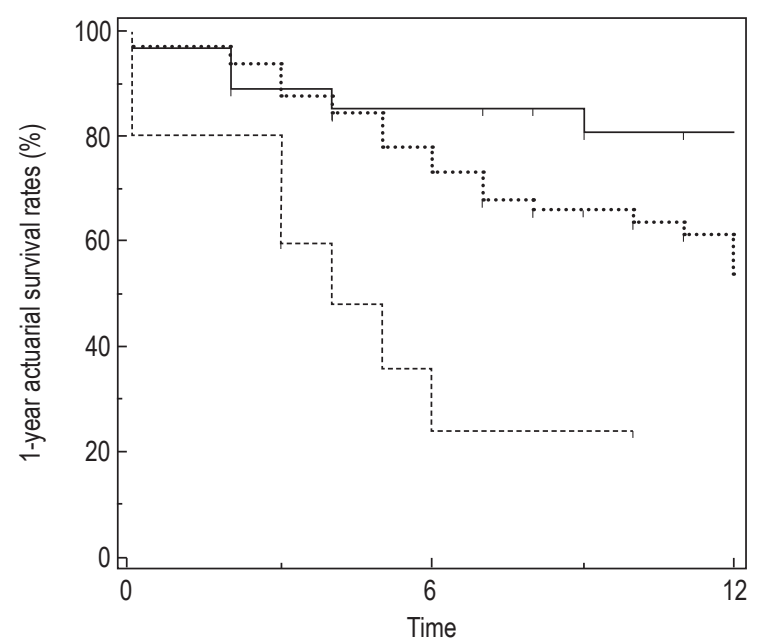

Figure 4-Kaplan-Meier survival by recursive partioning analysis (RPA) for 1-year actuarial survival rates. The solid line represents RPA Class I patients, the large dotted line represents RPA Class II patients and the small dotted line represents RPA Class III patients. (Logrank test $p=0.0016)$.

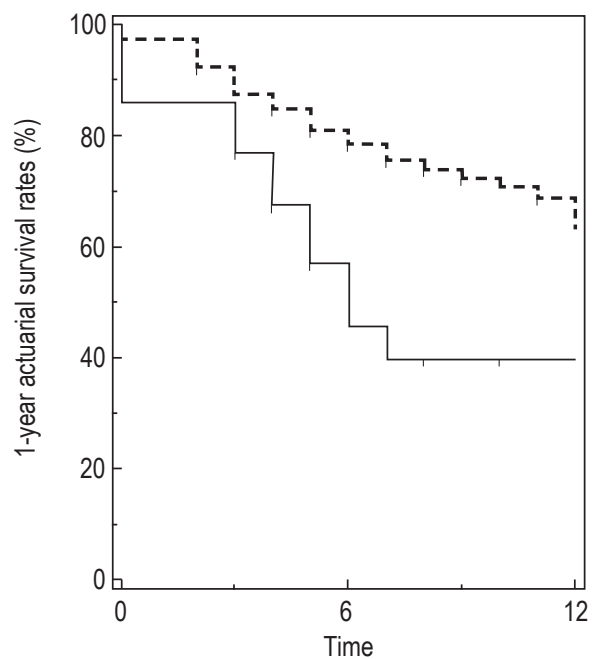

Figure 5 - Kaplan-Meier survival for KPS pre-treatment patients for 1-year actuarial survival rates. The solid line represents patients who had KPS $<70$ and the dotted line represents patients with $K P S \geq 70$ (Logrank test $p=0.0011)$. 


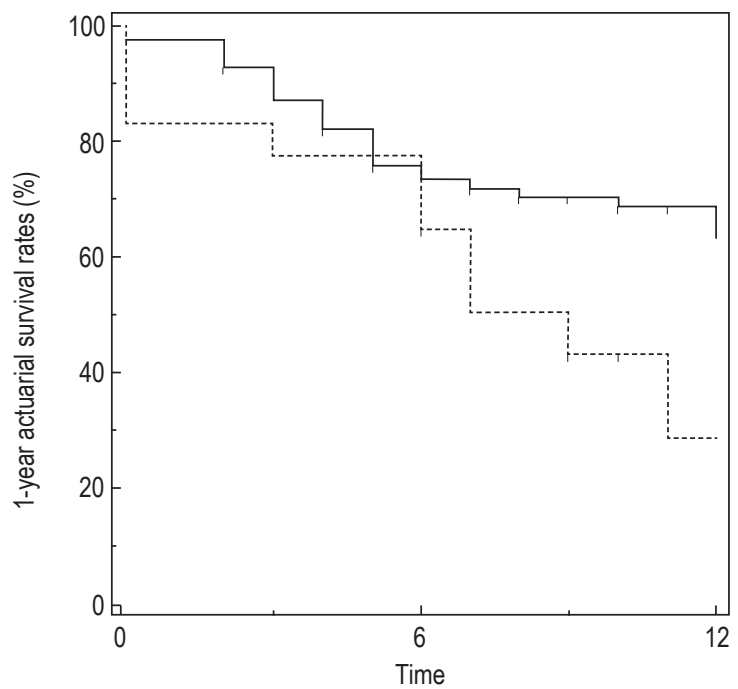

Figure 6-Kaplan-Meier survival by metastases volume for 1-year actuarial survival rates. The solid line represents patients who had metastases volume $<5 \mathrm{cc}$ and the dotted line represents patients with metastases volume $\geq 5 \mathrm{cc}$. (Logrank test $p=0.01$ ).

\section{Complications}

Two patients developed symptomatic radiation necrosis after SRS controlled with steroids. One patient developed obstructive hydrocephalus due to a radiationinduced edema of one brain stem metastasis, this complication being treated by means of a endoscopic third ventriculostomy. No patient died of radiation-induced complications.

\section{Discussion}

In autopsy series, brain metastasis occur in up to $50 \%$ of cancer patients. ${ }^{7}$ Approximately $30 \%$ to $40 \%$ present with a solitary metastasis. Brain metastasis frequently cause debilitating symptoms that can seriously affect the patient's quality of life. With no treatment or corticosteroid therapy alone, survival is very limited (1-2 months). WBRT extends median survival, but the duration of survival is typically low (3-4months). Several randomized trials have suggested that, whenever possible, surgery followed by WBRT is superior to WBRT alone. ${ }^{20}$ Patchell et al. ${ }^{13}$ reported a randomized clinical trial involving 46 patients with a single metastasis and well-controlled systemic disease. They found a significant improvement in survival (40 weeks vs 15 weeks) and local recurrences in the central nervous system ( $20 \%$ vs $52 \%$ ) for patients who underwent surgery plus WBRT.
SRS has emerged as a treatment option for such patients. It has been studied extensively as a minimally invasive alternative to surgical resection and also to provide improved local tumor control. ${ }^{1}$

The multi-institutional retrospective study by Auchter et al. ${ }^{1}$ demonstrated that patients with solitary brain metastasis meeting the criteria for surgery of Patchell et al. ${ }^{13}$ but treated with radiosurgery combined with WBRT had outcomes similar to those of patients treated with surgical resection combined with WBRT. O'Neill et al. ${ }^{12}$ compared surgical resection and radiosurgery, and found that 1-year survival was not statistically different but local control was significantly better with radiosurgery. Scoggle et al. ${ }^{16}$ analyzed 133 patients treated with either radiosurgery or surgery, followed by WBRT. Median survival was 12 months in the radiosurgery group and 9 months in the surgical group. Bindal et al. ${ }^{5}$ and Sawaya et al. ${ }^{15}$ attempted to retrospectively match surgical and radiosurgical group. They found median survival of 7.5 months in the radiosurgery group and 16.4 months in the surgery group. Radiosurgery has several theoretical advantages over surgical resection including application to surgically inaccessible lesions ${ }^{9}$ and greater efficacy in tumors considered "radio-resistant" such as melanoma ${ }^{11}$ and hypernephroma ${ }^{19}$.

In this study, median survival was 15 months. Increasing dose and volume $<5 \mathrm{cc}$ were associated with better local tumor control. Regional control was poorer in renal cancer patients. Non-stable extra-cranial disease (RPA III), pre-treatment neurological dysfunction (KPS $<70)$ and metastasis' volume $\geq 5 \mathrm{cc}$ were predictive of shorter survival.

Recently, debate has arisen regarding the use of radiosurgery alone as a primary treatment for brain metastasis. Proponents for the use of radiosurgery without WBRT cite incidence of subsequent dementia ${ }^{7}$ and lack of efficacy against "radio-resistant" histological findings as reasons for excluding WBRT. ${ }^{8}$ Others think that the addition of WBRT improves local and regional control rates. Aoyama et al. ${ }^{3}$ performed a randomized and prospective study in patients treated with radiosurgery alone versus radiosurgery plus WBRT. They demonstrated that SRS alone without upfront WBRT was associated with increased brain tumor recurrence; however, it did not result in either worsened neurological function or increased risk of neurological death. With respect to patient survival, the control of systemic cancer might outweigh the frequent recurrence of brain tumors. Sneed et al.$^{18}$ performed a retrospective analysis of survival and local control. Survival and local control were the same for both groups. Regional control was better in the WBRT group; however, new metastatic lesions could be successfully salvaged with repeated 
SRS treatment, leading to good intracranial control rates in both groups. In the present study, no significant survival and recurrence difference was observed between the groups receiving WBRT plus SRS and SRS alone, although the number of patients was not large enough to allow detection of any smaller difference.

\section{Conclusion}

SRS provided excellent local control with relatively low morbidity in patients with brain metastasis. Median survival was 15 months in this series. RPA class, KPS score and metastases' volume were the only significant factors predictive of survival. One-year local control was $81 \%$. Increased doses and tumors with volume $<$ $5 \mathrm{cc}$ accounted for better local control. One-year distant brain metastasis-free survival was $73 \%$. Renal cancer was the only predictive factor of poor regional control. Regional control, local tumor control and survival were not improved by the addition of WBRT.

\section{References}

1. Auchter RM, Lamond JP, Alexander E, Buatti JM, Chappell R, Friedman WA. A multiinstitutional outcome and prognostic factor analysis of radiosurgery for resectable single brain metastasis. Int J Radiat Oncol Biol Phys. 1996;35:27-35.

2. Andrews DW, Scott CB, Sperduto PW, Flanders AE, Gaspar LE, Schell MC. Whole brain radiation therapy with or without stereotatic radiosurgery boost for patients with one to three brain metastasis: phase III results of the RTOG 9508 randomized trial. Lancet. 2004;363:1665-72.

3. Ayoama H, Shirato H, Tago M, Nakagawa K, Toyoda T, Hatano K. Stereotatic radiosurgery plus whole-brain radiation therapy vs stereotatic radiosurgery alone for treatment of brain metástases. JAMA. 2006;295:2483-91.

4. Badley KA, Mehta MP. Management of brain metastases. Semin Oncol. 2004;31:639-701.

5. Bindal AK, Bindal RK, Hess KR, Shiu A, Hassenbusch SJ, Shi WM, Sawaya R. Surgery versus radiosurgery in the treatment if brain metastasis. J Neurosurg. 1996;84:748-54.

6. DeAngelis LM. Brain tumors. N Engl J Med. 2001;344:114-23.

7. DeAngelis LM, Delattre J, Posner JB. Radiation-induced dementia in patients cured of brain metastases. Neurology. 1989;39:789-96.
8. Grob JJ, Régis J, Laurans R, Delaunay M, Wolkenstein P, Paul K, et al. Radiosurgery without whole brain radiotherapy in melanoma brain metástases: Club de Cancérologie $\mathrm{Cu}$ tanée. Eur J Cancer. 1998;34:1187-92.

9. Huang C, Kondziolka D, Flickinger JC, Lunsford LD. Stereotatic radiosurgery for brainstem masses. J Neurosurg. 1999;91:563-8.

10. Kaplan EL, Méier P. Nonparametric estimation from incomplete observation. J Am Stat Assoc. 1958;53:457-81.

11. Mori Y, Kondziolka D, Flinkinger JC, Kirkwood JM, Agarwala S, Lunsford LD. Stereotatic radiosurgery for cerebral metastatic melanoma: Factors affecting local disease control and survival. Int J Radiat Oncol Biol Phys. 1998;42:581-9.

12. O'Neill BP, Iturria NJ, Link MJ, Pollock BE, Ballman KV, O'Fallon JR. A comparison of surgical ressection and stereotatic radiosurgery in the treatment of solitary brain metástases. Int J Radio Oncol Biol Phys. 2003;55:1169-76.

13. Patchell RA, Tibbs PA, Walsh JW, Dempsey RJ, Maruyama $\mathrm{Y}$, Kryscio RJ, et al. A randomized trial of surgery in the treatment of single metástases to the brain. N Engl J Med. 1990;322:494-500.

14. Patchell RA. The management of brain metástases. Cancer Treat Rev. 2003;29:533-40.

15. Sawaya R. Brain metastasis: Stell Knife or gamma knife. Ann Surg Oncol. 2000;7:323-4.

16. Schöggl A, Kitz K, Reddy M, Wolfsberger S, Schneider B, Dieckmann K, Ungersböck K. Defining the role of the stereotactic radiosurgery versus microsurgery in the treatment of single brain metástase. Acta Neurochir (Wien). 2000;142:621-6.

17. Shu HK, Sneed PK, Shiau CY, McDermott MW, Lamborn $\mathrm{KR}$, Park E, et al. Factors influencing survival after gamma knife radiosurgery for patients with single and multiple brain metástases. Cancer J Sci Am. 1996;2:335-42.

18. Sneed PK, Lamborn KR, Forstner JM, McDermott MW, Chang S, Park E, et al. Radiosurgery for brain metástases: Is whole brain radiotherapy necessary? Int J Radiat Oncol Biol Phys. 1999;43:549-58.

19. Ulm AJ, Friedman WA, Bova FJ, Bradshaw P, Amdur RJ, Mendenhall WM. Linear acceleratir radiosurgery in the treatment of brain metastasis. Neurosurgery. 2004;55:1076-85.

20. Wowra B, Siebels M, Muacevic A, Kreth FW, Mack A, Hofstetter A. Repeated Gamma Knife Surgery for multiple brain metástases from renal cell carcinoma. J Neurosurg. 2002;97:785-93.

Original recebido em abril de 2009

Aceito para publicação em setembro de 2009

Endereço para correspondência

Marcos Antônio Dellaretti Filho

Rua Santa Helena, 68/400

30220-240 - Belo Horizonte, $M G$

E-mail:mdellaretti@mac.com 